\title{
Prevalence and risk factors of suicidal ideations among patients with obsessive- compulsive disorder in Egypt
}

\author{
Mohammad Gamal Sehlo*, Usama Mahmoud Youssef and Hayam Mohammed El-Gohari
}

\begin{abstract}
Background: Suicidal ideations were reported in many studies among patient with obsessive-compulsive disorder (OCD); this study aimed to evaluate the prevalence and factors associated with current suicidal ideations among Egyptian patients with obsessive-compulsive disorder (OCD). A consecutive sample of 120 Egyptian OCD patients was included in the study. OCD was diagnosed using the structured clinical interview for DSM-V axis I disorders, clinical version (SCID-I-CV). Yale-Brown Obsessive Compulsive Scale (Y-BOCS) was also applied to the patients. Presence of current suicidal ideations was assessed using Scale for Suicidal Ideation (SSI).

Results: Twenty eight (23.3\%) of the OCD patients reported presence of current suicidal ideations, religious obsessions $\mathrm{OR}=3.53, P=0.009$, and presence of comorbid major depressive disorder $\mathrm{OR}=1.77, P=0.04$.

Conclusion: Religious obsessions and comorbid major depressive disorder were found to be significant predictors for the current suicidal ideations in patients with OCD; however, religious obsessions were the strongest predictor. Religious obsessions should be evaluated and treated to decrease the risk of suicidal thoughts in Egyptian OCD patients.
\end{abstract}

Keywords: Risk factors, Suicidal ideations, Obsessive-compulsive disorder

\section{Background}

Suicidal behavior is a continuum process that ranges from suicidal ideation to attempting and eventually completing the suicide $[1,2]$. Suicidal ideation was defined as any self-reported thoughts of engaging in suiciderelated behavior [3]. Suicidal behavior among patients with anxiety disorders is much higher than in the general population [4]. OCD is ranked among the 10 most disabling medical conditions worldwide [5]. Obsessions and compulsions cause functional impairment, interfering with leisure activities and affecting family, marital, and social relationships [6-8].

Studies reported significantly higher rates of suicidal behavior among patients with OCD. Kamath et al. [9] reported that OCD is associated with a high risk of

*Correspondence: sehlo68@gmail.com

Department of Psychiatry, Faculty of Medicine, Zagazig University, P.O. Box 44519, Zagazig, Sharkia, Egypt

\section{Springer Open}

suicidal behavior. Torres et al. [10] found that $63 \%$ of OCD patients reported lifetime suicidal thoughts, and $25 \%$ reported at least one previous suicide attempt. Little is known about the risk factors of suicidal behavior among patients with OCD in Arab countries. Comorbidity with depression [9] and substance abuse [11] have been suggested as risk factors of suicidal behavior among patients with OCD in previous studies.

One of the most important aspects of psychiatric practice is to prevent deaths by suicide [12]. Suicidal ideations are considered as a precursor for suicidal attempts and completed suicide among psychiatric patients [13]. Recognition and treatment of the risk factors of suicidal ideations among patients with OCD are crucial in preventing fatal consequences. The aims of this study were to assess the prevalence of suicidal ideations and the factors associated with suicidal ideations in patients with obsessive compulsive disorder in Egypt. 


\section{Methods}

\section{Participants}

A sample of 120 consecutive patients with obsessivecompulsive disorder (OCD) was included in this crosssectional study. The patients were recruited from the outpatient clinic of the Psychiatry Department, Zagazig University Hospital, Zagazig, Egypt, between January 2019 and October 2019. Both male and female patients aged 18 to 60 years old were included in the study. Exclusion criteria are any medical or psychiatric comorbidity. The sample was categorized into 2 groups, those with current suicidal ideations (group I) and those without current suicidal ideations (group II), by using the Scale for Suicidal Ideation (SSI).

\section{Measures}

Sociodemographic form is composed of questions related to personal characteristics of patients (age, gender, education, marital status, employment status family history of OCD, and disorder duration).

The Structured Clinical Interview for the DSM axis I disorders, clinical version (SCID-I-CV) was used to confirm the diagnosis OCD and to diagnose other Axis I comorbid disorders [14].

Yale-Brown Obsessive Compulsive Scale (Y-BOCS) was used to measure the presence and severity of obsessions and compulsions. The Y-BOCS is considered the "gold standard" for assessing symptom severity [15]. The Y-BOCS is divided into two sections; the first section is a checklist of obsessions and compulsions. The second section contains 12 questions about the severity of obsession-compulsive symptoms. Responses are made on a Likert scale from 0 (no symptoms) to 4 (extreme symptoms) with higher scores indicating greater severity. The first ten items assess the time spent, the degree of distress and interference, and the perceived resistance to and control over obsessions and compulsions. The sum of the 10 severity items yields three scores: an obsession severity score (range $=0-20$ ), a compulsion severity score (range $=0-20$ ), and a total score (range $=0-40$ ). The Y-BOCS also contains two additional items that measure important features of OCD; item 11 measures the degree to which the respondents recognized that their obsessions and compulsions are unreasonable or senseless, and item 12 measures the extent to which respondents avoid doing things, going places, or being with people because of their obsessions and compulsions. Psychometric estimates of the Y-BOCS suggest excellent reliability and validity $[16,17]$.

Scale for Suicidal Ideation (SSI) was used to assess the suicidal ideations in patients with OCD; the SSI is a clinician rating scale with a semi-structured interview format [18], with established reliability and validity [19]. This 19-item scale evaluates intensity of the patient's active suicide desire, specific plans for suicide, passive suicide desire, and previous suicide attempts. Each item consists of three choices graded according to the intensity of the suicidality and rated on a 3-point scale ranging from 0 to 2 . Higher scores are related to severe suicidal ideation. A total SSI score equivalent to 6 or more was considered as a cutoff point for clinically significant suicidal ideations as suggested in a previous study on adult suicidality [20]. We used this cutoff point to evaluate the presence of suicidal ideations.

Previous history of suicide attempts, defined as an act of deliberate self-destructive behavior with the intension of ending one's life, was assessed retrospectively by asking the patients directly "Have you ever attempted suicide?"

\section{Statistical analysis}

The data were analyzed using the Statistical Package for the Social Sciences (SPSS Inc., Chicago, IL, USA), version 20. Descriptive data were analyzed using means, standard deviation, and percentages. $T$ test was used to compare quantitative parameters. Regression methods were used to develop predictive models. A $P$ value $<.05$ was considered to indicate statistical significance.

\section{Results \\ Demographic and clinical characteristics of study participants}

Of the 120 OCD patients, 28 (23.3\%) were found to have current suicidal ideations. There were no statistically significant differences between the OCD patients with current suicidal ideations (group I) and those without current suicidal ideations (group II) in terms of age, gender, years of education, duration of OCD, employment status, marital status, family history of OCD, and total Y-BOCS mean score. There was a significant increase in the number of previous hospitalizations, the number of patients diagnosed with major depressive disorder, and patients with past suicidal attempts in group I compared with group II ( $P=<0.001,0.01$, and 0.02 respectively). Also, there was a significant increase in the number of patients with religious obsessions in group I compared with group II $(P=0.03)$ (Tables 1 and 2 ).

\section{Results of regression analysis}

Using logistic regression for the whole sample, we found that presence of religious obsessions was the strongest predictor for current suicidal ideations, with 3 times increased risk for suicidal ideations $(\mathrm{OR}=3.53, \mathrm{CI}=$ 1.96-5.11, $P=0.009$ ), and presence of comorbid major depressive disorder was also a significant predictor for current suicidal ideations, with 1.5 times increased risk for suicidal ideations $(\mathrm{OR}=1.77, \mathrm{CI}=1.21-3.86, \quad P=$ 0.04) (Table 3). 
Table 1 Demographic and clinical characteristics of OCD patients with and without current suicidal ideations $(n=120)$

\begin{tabular}{|c|c|c|c|c|c|c|c|}
\hline \multirow[t]{2}{*}{ Variable } & \multicolumn{2}{|c|}{ With suicidal ideations $(N=28)$} & \multicolumn{2}{|c|}{ Without suicidal ideations $(N=92)$} & \multicolumn{2}{|c|}{ Significance } & \multirow[t]{2}{*}{$\mathrm{Cl}(95 \%)$} \\
\hline & $\bar{M}$ & SD & $\bar{M}$ & SD & $t$ & $p$ & \\
\hline Age & 34.78 & 5.99 & 36.69 & 7.52 & -0.92 & 0.3 & $-6.06-2.24$ \\
\hline Education (in years) & 12.94 & 4.72 & 12.01 & 5.13 & 0.64 & 0.5 & $-2.01-3.90$ \\
\hline Duration of OCD (in years) & 7.94 & 2.79 & 6.59 & 3.21 & 1.49 & 0.1 & $-0.46-3.17$ \\
\hline \multirow[t]{2}{*}{ Number of previous hospitalizations } & 5.22 & 2.13 & 3.03 & 1.76 & 3.90 & $<0.001$ & $1.06-3.31$ \\
\hline & N & $\%$ & N & $\%$ & $x^{2}$ & $p$ & \\
\hline \multicolumn{8}{|l|}{ Gender } \\
\hline Female & 13 & 46.40 & 47 & 51 & 0.19 & 0.6 & \\
\hline Male & 15 & 53.60 & 45 & 49 & & & \\
\hline \multicolumn{8}{|l|}{ Employment status } \\
\hline Employed & 20 & 71.42 & 64 & 69.56 & 0.04 & 0.8 & \\
\hline Unemployed & 8 & 28.58 & 28 & 30.44 & & & \\
\hline \multicolumn{8}{|l|}{ Marital status } \\
\hline Married & 20 & 71.42 & 74 & 80.43 & 0.49 & 0.4 & \\
\hline Single & 5 & 17.85 & 11 & 11.95 & & & \\
\hline Divorced & 2 & 7.15 & 3 & 3.27 & & & \\
\hline Widowed & 1 & 3.58 & 4 & 4.35 & & & \\
\hline Family history of OCD & $7 / 28$ & 25 & $22 / 92$ & 23.91 & 0.01 & 0.9 & \\
\hline \multicolumn{8}{|l|}{ Axis-I co morbidity } \\
\hline Major depressive disorder & $14 / 28$ & 50 & $23 / 92$ & 25 & 6.29 & 0.01 & \\
\hline Generalized anxiety disorder & $6 / 28$ & 21.42 & $16 / 92$ & 17.39 & 0.23 & 0.6 & \\
\hline Panic disorder & $1 / 28$ & 3.58 & 2/92 & 2.17 & 0.17 & 0.6 & \\
\hline Past suicidal attempts & $4 / 28$ & 14.28 & $3 / 92$ & 3.26 & 4.75 & 0.02 & \\
\hline
\end{tabular}

\section{Discussion}

In the current study, 28/120 (23.3\%) were found to have current suicidal ideations. This in line with other studies that reported 27\% [19] increased likelihood of current suicidal ideations in patients with OCD. Chaudhary et al. and Breet et al. reported $52 \%$ and $51.8 \%$ of suicidal ideations respectively among OCD patient; they used different tools for suicide estimations such as Columbia suicide severity rating scale (CSSRS) [21, 22].

In agreement with the literature, many studies reported that major depression is strongly associated with suicidal ideations among patients with OCD $[9,21$, 23-27]. In contrast, Apter et al. reported inverse relationship between depression and suicidal behavior in a group of adolescents suffering from OCD, but the OCD patients that were included in our study were adults. So treatment of comorbid depression is important to decrease the risk of suicide among patients with OCD [28].

The most important finding in the present study was that the presence of religious obsessions was the strongest predictor for the current suicidal ideations among Egyptian Muslim patients with OCD. In Egypt, where this study was carried out, a predominantly Islamic society is governed by traditional cultural and Islamic values
[29], so religious obsessions are extremely painful and stressful than other subtype obsessions in this society; this is on line with a recent Egyptian study that reported similar results [30].

Torres et al. reported that symptoms from the sexual/ religious dimension were the most consistent with all aspects of suicidal behavior among patients with OCD, and also, Kamath et al. [9] reported that religious symptoms were the only ones significantly associated with suicide among patients with OCD. Chaudhary et al. reported that suicidality was found to be maximum in those with symptoms of cleanliness and contamination (57\%) followed by religious obsessions (45\%), sexual obsessions (33\%), repeated rituals (31\%), and other obsessions like need to touch and ask (26\%) respectively. This result can be explained by the different culture and suicide religious believes [10, 21, 31, 32].

Balci and Sevincok [27] found that Muslim OCD patients with suicidal ideations tended to have more religious obsessions than patients without suicidal ideations but this difference failed to reach a significance; this may be due to their small sample size.

Similar to the results of the current study, Balci and Sevincok found that the severity of depression differed 
Table 2 OCD clinical characteristics comparison between OCD patients with and without current suicidal ideations $(n=120)$

\begin{tabular}{|c|c|c|c|c|c|c|c|}
\hline \multirow[t]{2}{*}{ Variable } & \multicolumn{2}{|c|}{ With suicidal ideations $(N=28)$} & \multicolumn{2}{|c|}{ Without suicidal ideations $(N=92)$} & \multicolumn{2}{|c|}{ Significance } & \multirow[t]{2}{*}{$\mathrm{Cl}(95 \%)$} \\
\hline & $M$ & SD & $M$ & SD & $t$ & $p$ & \\
\hline \multirow[t]{2}{*}{ Total Y-BOCS } & 27.61 & 3.32 & 26.69 & 4.13 & 0.81 & 0.4 & $3.91-8.22$ \\
\hline & N & $\%$ & N & $\%$ & $x^{2}$ & $p$ & \\
\hline \multicolumn{8}{|l|}{ Obsessions } \\
\hline Contamination & 9 & 32.1 & 31 & 33.7 & 0.02 & 0.8 & \\
\hline Aggressive & 3 & 10.6 & 11 & 12 & 0.03 & 0.8 & \\
\hline Sexual & 4 & 14.1 & 15 & 16.5 & 0.07 & 0.7 & \\
\hline Hoarding & 2 & 7.7 & 7 & 7.6 & 0.01 & 0.9 & \\
\hline Religious & 8 & 28.5 & 11 & 12 & 4.45 & 0.03 & \\
\hline Symmetry & 1 & 3.5 & 8 & 8.6 & 0.81 & 0.3 & \\
\hline Somatic & 1 & 3.5 & 9 & 9.6 & 1.08 & 0.2 & \\
\hline Miscellaneous & 0 & 0 & 0 & 0 & 0 & 0 & \\
\hline \multicolumn{8}{|l|}{ Compulsions } \\
\hline Cleaning & 9 & 32.1 & 31 & 33.7 & 0.02 & 0.8 & \\
\hline Checking & 6 & 21.3 & 15 & 16.5 & 0.39 & 0.5 & \\
\hline Ritualistic & 6 & 21.3 & 18 & 19.3 & 0.05 & 0.8 & \\
\hline Counting & 4 & 14.1 & 13 & 14.3 & 0.01 & 0.9 & \\
\hline Arranging/ordering & 1 & 3.5 & 8 & 8.6 & 0.81 & 0.8 & \\
\hline Hoarding & 2 & 7.7 & 7 & 7.6 & 0.01 & 0.9 & \\
\hline Miscellaneous & 0 & 0 & 0 & 0 & 0 & 0 & \\
\hline
\end{tabular}

Total Y-BOCS Yale-Brown Obsessive Compulsive Scale

significantly between patients who have suicide ideations and those who have not, but they found that the aggressive obsessions were the most predictors of suicide among OCD, that result was not in line with the current one, and it can be explained by the small sample size of their study [27].

Another study by Velloso et al. reported correlation between suicide phenomenon and religious dimension of OCD symptoms [33].

So searching for presence of religious obsessions among Arab Muslim patients with suicidal ideations suffering from OCD is mandatory, and cognitivebehavioral therapy is essential to resolve the marked stress associated with the religious obsessions, and subsequently, this will decrease these obsessions.

The current study has a number of limitations. The study is cross-sectional, and longitudinal studies are required to prove causality. Also, we did not assess other variables that may be associated with suicidal ideations among patients with OCD such as personality traits, past history of childhood trauma, and substance abuse. Despite these limitations, to our knowledge, this study is

Table 3 Logistic regression analysis predicting presence of current suicidal ideations among patients with OCD (N=120).

\begin{tabular}{|c|c|c|c|c|c|c|}
\hline Dependent variable & Model & Independent variables & $B$ & $P$ & Odds ratio & $95 \% \mathrm{Cl}$ \\
\hline \multirow[t]{6}{*}{ Presence of current suicidal ideations } & $\begin{array}{l}R^{2}=0.58 \\
X^{2}=24.78 \\
P=0.006\end{array}$ & Presence of religious obsessions & $\begin{array}{l}0.58 \\
0.87\end{array}$ & 0.009 & 3.53 & $1.96-5.11$ \\
\hline & & Comorbid major depressive disorder & 0.28 & 0.04 & 1.77 & $1.21-3.86$ \\
\hline & & OCD severity (*Total Y-BOCS) & 0.09 & 0.7 & 0.87 & $0.71-1.01$ \\
\hline & & Duration of OCD & 0.10 & 0.8 & 0.89 & $0.60-1.01$ \\
\hline & & Number of previous hospitalizations & 0.06 & 0.6 & 0.86 & $0.68-1.00$ \\
\hline & & Previous suicidal attempts & 0.12 & 0.6 & 0.91 & $0.72-1.03$ \\
\hline
\end{tabular}

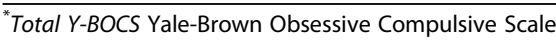


one of the few studies that has evaluated the relationship of religious obsessions and suicidal ideations among Egyptian Muslim population suffering from OCD.

\section{Conclusion}

In the present study, presence of religious obsessions and comorbid major depressive disorder was found to be significant predictors for the current suicidal ideations in Egyptian patients with OCD. Presence of religious obsessions was the strongest predictor for the current suicidal ideations in those patients. These factors should be considered in the treatment regimen and resolving the marked stress associated with the presence of religious obsessions and subsequently increased risk for suicidal behavior is mandatory.

\section{Acknowledgements}

The authors would like to thank all participants in the study.

\section{Authors' contributions}

MS: concept and design. MS, UY, and HG: data collection and interpretation of the data, writing of the draft. All authors read and approved the study.

\section{Funding}

None

\section{Availability of data and materials}

All data generated or analyzed during this study are included in this published article.

\section{Ethics approval and consent to participate}

After complete description of the study to the subjects, informed consent was obtained. The ethical approval was obtained from the research ethics committee of the faculty of medicine, Zagazig University, under number 6486.

\section{Consent for publication}

Not applicable

\section{Competing interests}

The authors declare no conflict of interest.

Received: 8 December 2020 Accepted: 18 January 2021

Published online: 10 February 2021

\section{References}

1. Bertolote JM, Fleischmann A, De Leo D, Bolhari J, Botega N, De Silva D, Tran Thi Thanh H, Phillips M, Schlebusch L, Varnik A, Vijayakumar L, Wasserman D (2005) Suicide attempts, plans, and ideation in culturally diverse sites: the WHO SUPRE-MISS community survey. Psychol Med 35:1457-1465

2. Nock MK, Borges G, Bromet EJ et al (2008) Cross-national prevalence and risk factors for suicidal ideation, plans and attempts. Br J Psychiatry 192:98105

3. O'Carroll PW, Berman AL, Maris RW, Moscicki EK, Tanney BL, Silverman MM (1996) Beyond the Tower of Babel: a nomenclature for suicidology. Suicide Life Threat Behav 26:237-252

4. Khan A, Leventhal RM, Khan S, Brown WA (2002) Suicide risk in patients with anxiety disorders: a meta-analysis of the FDA database. J Affect Disord 68:183-190

5. Murray C, Lopez A (1996) Global health statistics: a compendium of incidence, prevalence, and mortality estimates for over 200 conditions. Harvard University Press, Cambridge

6. Gururaj GP, Math SB, Reddy JY, Chandrashekar CR (2008) Family burden, quality of life and disability in obsessive compulsive disorder: an Indian perspective. J Postgrad Med 54:91-97

7. Mortiz S (2008) A review on quality of life and depression in obsessivecompulsive disorder. CNS Spectr 13:16-22
8. Niederauer KG, Braga DT, Souza FP, Meyer E, Cordioli AV (2007) Quality of life in individuals with obsessive-compulsive disorder: a review. Rev Bras Psiquiatr 29:271-278

9. Kamath P, Reddy YC, Kandavel T (2007) Suicidal behavior in obsessivecompulsive disorder. J Clin Psychiatry 68:1741-1750

10. Torres AR, Prince MJ, Bebbington PE, Bhugra D, Brugha TS, Farrell M, Jenkins R, Lewis G, Meltzer $H$, Singleton N (2006) Obsessive-compulsive disorder: prevalence, comorbidity, impact, and help-seeking in the British National Psychiatric Morbidity Survey of 2000. Am J Psychiatry 163:1978-1985

11. Gentil AF, de Mathis MA, Torresan RC, Diniz JB, Alvarenga P, do Rosario MC, Cordioli AV, Torres AR, Miguel EC (2009) Alcohol use disorders in patients with obsessive-compulsive disorder: the importance of appropriate dualdiagnosis. Drug Alcohol Depend 100:173-177

12. Gershon ES (2007) Genes and environment in suicidality. Am J Psychiatry 164:1460-1461

13. Joiner TE Jr, Ster RA, Brown G, Beck AT, Pettit JW, Rudd MD (2003) Worstpoint suicidal plans: a dimension suicidality predictive of past suicide attempts and eventual death by suicide. Behav Res Ther 41:1469-1480

14. First MB, Spitzer RL, Gibbon M, Williams JBW (1997) Structured clinical interview for DSM-IV Axis I Disorders-Clinical Version (SCID-CV). American Psychiatric Publishing, Inc, Washington

15. Frost RO, Steketee G, Krause MS, Trepanier KL (1995) The relationship of the Yale-Brown Obsessive Compulsive Scale (Y-BOCS) to other measures of obsessive compulsive symptoms in a nonclinical population. J Pers Assess 65:158-168

16. Goodman WK, Price LH, Rasmussen SA, Mazure C (1989) The Yale-Brown Obsessive Compulsive Scale. II: validity. Arch Gen Psychiatry 46:1012-1016

17. Goodman WK, Price LH, Rasmussen SA, Mazure C, Fleischmann RL, Hill CL, Heninger GR, Charney DS (1989) The Yale-Brown Obsessive Compulsive Scale. I: development, use, and reliability. Arch Gen Psychiatry 46:1006-1011

18. Beck AT, Kovacs M, Weissman A (1979) Assessment of suicidal intension: the Scale for Suicide Ideation. J Consult Clin Psychol 47:343-352

19. Beck AT, Steer RA, Beck JS, Newman CF (1993) Hopelessness, depression, suicidal ideation, and clinical diagnosis of depression. Suicide Life Threat Behav 23:139-145

20. Socero TP, Melartin TK, Rytsala HJ, Leskela US, Lestela-Mielonen PS, Isometsa ET (2003) Suicidal ideation and attempts among psychiatric patients with major depressive disorder. J Clin Psychiatry 64:1094-1100

21. Chaudhary R, Kumar P, Mishra BP (2016) Depression and risk of suicide in patients with obsessive-compulsive disorder: a hospital-based study. Ind Psychiatry J 25(2):166-170

22. Breet E, Kidd M, McGregor NW, Stein DJ, Lochner C (2019) Suicide ideation and attempts in obsessive-compulsive disorder. Ann Clin Psychiatry 31(3): 192-199

23. Tukel R, Meteris H, Koyuncu A, Tecer A, Yazici O (2006) The clinical impact of mood disorder comorbidity on obsessive-compulsive disorder. Eur Arch Psychiatry Clin Neurosci 256:240-245

24. Denys D, Tenney N, vanMegen HJ, de Geus F, Westenberg HG (2004) Axis I and II comorbidity in a large sample of patients with obsessive-compulsive disorder. J Affect Disord 80:155-162

25. Nestadt G, Di CZ, Riddle MA, Grados MA, Greenberg BD, Fyer AJ, McCracken JT, Rauch SL, Murphy DL, Rasmussen SA, Cullen B, Pinto A, Knowles JA, Piacentini J, Pauls DL, Bienvenu OJ, Wang Y, Liang KY, Samuels JF, Bandeen Roche K (2009) Obsessive-compulsive disorder: subclassification based on co-morbidity. Psychol Med 39(9):1491-1501

26. Alonso P, Segalas C, Real E, Pertusa A, Labad J, Jimenez-Murcia S, Jaurrieta N, Bueno B, Vallejo J, Menchon JM (2010) Suicide in patients treated for obsessive-compulsive: a prospective follow up study. J Affect Disord 124: 300-308

27. Balci V, Sevincok L (2010) Suicidal ideation in patients with obsessivecompulsive disorder. Psychiatry Res 175:104-108

28. Apter A, Horesh N, Gothelf D, Zalsman G, Erlich Z, Soreni N, Weizman A (2003) Depression and suicidal behavior in adolescents inpatients with obsessive-compulsive disorder. J Affect Disord 75:181-189

29. Bernard L (1994) The shaping of the modern Middle East. Oxford University Press, New York

30. Nagy N, El-Serafi D, Elrassas H, Abdeen M, Mohamed D (2020) Impulsivity, hostility and suicidality in patients diagnosed with obsessive compulsive disorder, Int J Psychiatry Clin Pract. 24(3):284-292

31. Torres AR, Ramos-Cerqueira AT, Ferrao YA, Fontenelle LF, do Roario MC Miguel EC (2011) Suicidality in obsessive-compulsive disorder: prevalence 
and relation to symptom dimensions and comorbid conditions. J Clin Psychiatry 72:17-26

32. Torres AR, de Abreu Ramos-Cerqueira AT, Torresan RC, de Souza Domingues M, Hercos AC, Guimaraes AB (2007) Prevalence and associated factors for suicidal ideation and behaviors in obsessive-compulsive disorder. CNS Spectr 12:771-778

33. Velloso P, Piccinato C, Ferrão Y, Aliende Perin E, Cesar R, Fontenelle L, Hounie AG, do Rosário MC (2016) The suicidality continuum in a large sample of obsessive-compulsive disorder (OCD) patients. Epub Psychiatry $38: 1-7$

\section{Publisher's Note}

Springer Nature remains neutral with regard to jurisdictional claims in published maps and institutional affiliations.

\section{Submit your manuscript to a SpringerOpen ${ }^{\circ}$ journal and benefit from:}

- Convenient online submission

- Rigorous peer review

- Open access: articles freely available online

- High visibility within the field

- Retaining the copyright to your article

Submit your next manuscript at $\boldsymbol{\nabla}$ springeropen.com 